\title{
SENSORS AND MATERIALS
}

\section{МАТЕРІАЛИ ДЛЯ СЕНСОРІВ}

УДК 517.312:621.315.592

DOI 10.18524/1815-7459.2016.4.86655

\section{ЧУВСТВИТЕЛЬНОСТЬ ЭЛЕКТРОПРОВОДНОСТИ КЕРАМИКИ $\mathrm{ZnO} \mathrm{С} \mathrm{ДОБАВКОЙ}$ СЕРЕБРА К МЕТАНУ}

\author{
Е. Л. Повзло, А. Ю. Лячков, А. С. Тонкошкур
}

Днепропетровский национальный университет им. О. Гончара 49010, Украина, Днепр, пр. Гагарина, 72, каф. радиоэлектроники, тел.+380638409592, e-mail:vdnu@yandex.ua

\section{ЧУВСТВИТЕЛЬНОСТЬ ЭЛЕКТРОПРОВОДНОСТИ КЕРАМИКИ $\mathrm{ZnO} \mathrm{С} \mathrm{ДОБАВКОЙ}$ СЕРЕБРА К МЕТАНУ}

\author{
Е. Л. Повзло, А. Ю. Ляшков, А. С. Тонкошкур
}

\begin{abstract}
Аннотация. Целью работы было экспериментальное исследование чувствительности электропроводности керамики $\mathrm{ZnO}$ с добавкой серебра к присутствию в воздушной среде метана.

Показано, что исследованная керамика обладает достаточно высокой чувствительностью электропроводности к метану, сравнимой со значениями для других газообразных углеводородов. Ее увеличение может быть достигнуто введением в керамику добавки серебра, что приводит к уменьшению ее плотности.

Установлено, что чувствительность исследованной керамики имеет некоторую селек-тивность. Это проявляется в смещении максимума температурной зависимости отклика в сторону высоких температур для углеводородов с большей молекулярной массой (пропан, бутан) в сравнении с метаном.

Ключевые слова: оксид цинка, серебро, сенсор, газочувствительность, электропроводность, метан, керамика, межкристаллитные барьеры
\end{abstract}

(C) Є. Л. Повзло, О. Ю. Ляшков, О. С. Тонкошкур, 2016 
ЧУТЛИВІСТЬ ЕЛЕКТРОПРОВІДНОСТІ КЕРАМІКИ ZnO 3 ДОМІШКОЮ СРІБЛА ДО МЕТАНУ

\author{
Є. Л. Повзло, О. Ю. Ляшков, О. С. Тонкошкур
}

\begin{abstract}
Анотація. Метою роботи було експериментальне дослідження чутливості електропровідності кераміки $\mathrm{ZnO} з$ домішкою срібла до присутності в повітряному середовищі метану, а також зіставлення отриманих результатів з даними про газочутливість цієї кераміки до інших вуглеводнів.

Показано, що досліджена кераміка має досить високу чутливість електропровідності до метану, порівнянної зі значеннями для інших газоподібних вуглеводнів. Ї̈̈ збільшення може бути досягнуто введенням в кераміку домішки срібла, що призводить до зменшення іï густини.

Встановлено, що чутливість дослідженої кераміки має деяку селективність. Це проявляється в зміщенні максимуму температурної залежності відгуку в сторону високих температур для вуглеводнів з більшою молекулярною масою (пропан, бутан) в порівнянні з метаном.

Ключові слова: оксид цинку, срібло, сенсор, газочутливість, електропровідність, метан, кераміка, міжкристалітні бар'єри
\end{abstract}

\title{
SENSITIVITY CONDUCTIVITY OF THE CERAMIC ZnO WITH ADDITION OF SILVER TO METHANE
}

\author{
E. L. Povzlo, A. Yu. Lyashkov, A. S. Tonkoshkur
}

\begin{abstract}
Purpose of the paper was the experimental research of sensitivity of the electrical conductivity of $\mathrm{ZnO}$ ceramics with the addition of silver to the presence of methane in the air environment, and also obtained results were compared with data of gas sensitivity of ceramics to other hydrocarbons.

It is shown that the conductivity of the ceramic has a sufficiently high sensitivity to methane and is comparable with the values for other gaseous hydrocarbons. Its increase can be achieved by adding silver into the ceramic additive that reduces its density.

It found that the sensitivity of the leaned ceramics has a certain selectivity. This is detected by the displacement maximum of the temperature dependence of response to higher temperatures for the hydrocarbons with a higher molecular weight (propane, butane) in comparison with methane.

Keywords: Zinc oxide, silver, sensor, gas sensing, electrical conductivity, ceramics, methane, grain boundary
\end{abstract}




\section{1. Введение}

Оксид цинка является одним из наиболее известных материалов для разработки полупроводниковых газовых сенсоров [1-5]. Среди перспективных газочувствительных структур на его основе особое место занимает керамика $\mathrm{ZnO}$ с добавкой серебра. С одной стороны она приемлема для разработки полупроводниковых резистивных газовых сенсоров [6,7]. С другой стороны достаточно высокий уровень исследованности структурных особенностей и электронных процессов в таком материале делает его наиболее удобным для теоретических исследований явления газочувствительности к разным газовым окружениям [8-12].

Следует отметить, что структуры из керамического $\mathrm{ZnO}$ с добавкой серебра обладают достаточно высокой чувствительностью электропроводности к парам спиртов $[2,4,12]$. В частности, они обнаруживают селективную чувствительность изменения электропроводности (отклик) к парам предельных одноатомных спиртов, что проявляется в температурных зависимостях отклика, кинетических зависимостях и зависимостях отклика от парциального давления паров $[13,14]$.

В последнее время, особое внимание уделяется изучению особенностей газовой чувствительности электропроводности керамики $\mathrm{ZnO}$ с добавкой $\mathrm{Ag}$ к газообразным углеводородам. Так в [15] получены данные о применимости близкого по составу к рассматриваемой керамике сенсорного материала, состоящего из наночастиц $\mathrm{Ag}$ и $\mathrm{ZnO}$ с примесью графена для детектирования ацетилена. В [16] показана перспективность применения керамики $\mathrm{ZnO}$ с добавкой $\mathrm{Ag}$ к детектированию пропан-бутановой смеси.

Механизмы электронного обмена между поверхностью полупроводника и адсорбирующимися газами во многих случаях очень схожи. Поэтому выявление индивидуальных особенностей газов в формировании газочувствительных характеристик сенсора является актуальной задачей, чему и посвящена данная работа.

В настоящей работе приводятся результаты экспериментальных исследований чувствительности электропроводности одной из наиболее перспективных керамик на основе $\mathrm{ZnO}$ с добавкой серебра к метану, находящемуся в воздушной среде.

\section{2. Образцы и методика эксперимента}

Использовались образцы, изготовленные из порошков $\mathrm{ZnO}$ и $\mathrm{Ag}_{2} \mathrm{O}$ субмикронного размера по описанной в [16] керамической технологии. Количество добавки $\mathrm{Ag}_{2} \mathrm{O}$ варьировалось от $0,001 \%$ до 3\% по массе. Фазовый состав, микроструктура и электрофизические параметры керамики ZnO-Ag описаны в работе [12]. Образцы представляли собой поликристаллические структуры. Кристаллиты оксида цинка имели средние размеры 300-400 нм. В структурах имелись также вкрапления металлического серебра. Электрические свойства керамики соответствовали представлениям о наличии между зернами ZnO межкристаллитных потенциальных барьеров.

При исследованиях газочувствительных свойств изготовленной керамики в изолированную измерительную камеру объемом 20 дм $^{3}$ наполненную воздухом находящимся при атмосферном давлении вводили необходимое количество метана. Метан синтезировался лабораторным методом путем нагревания смеси гидроксида натрия и ацетата натрия [17]:

$$
\mathrm{CH}_{3} \mathrm{COONa}+\mathrm{NaOH}=\mathrm{Na}_{2} \mathrm{CO}_{3}+\mathrm{CH}_{4} .
$$

Для сравнения полученных результатов с данными для других газообразных углеводородов использовалась пропанбутановая смесь марки ПБА (пропан-бутан автомобильный), содержащий $50 \pm 10 \%$ пропана, бутан и не более $6 \%$ непредельных углеводородов [16].

Концентрация газа в воздушной среде нормировалась по отношению к концентрации молекул газа при нормальных условиях $\left(n_{C H 4} / n_{0}\right.$, где $\mathrm{n}_{0}-$ концентрация молекул воздуха в условиях эксперимента) [16]. Эта величина в условиях эксперимента не превышала 2\%. Для восстановления электрических свойств образца после каждого эксперимента он прогревался на воздухе при $T \sim 720 \mathrm{~K}$ в течении 20 мин. От- 
клик сенсора определялся как $\Delta \sigma / \sigma_{0}$, где $\Delta \sigma=\sigma-\sigma_{0} ; \sigma-$ электропроводность сенсора в среде содержащей адсорбат, $\sigma_{0}$ электропроводность на воздухе.

Кинетика отклика изучалась путем помещения-извлечения сенсора в измерительную камеру. Зависимости отклика от парциального давления и температуры использованных газообразных углеводородов были получены на основе кривых кинетики изменения электропроводности путем фиксации значений через определенный промежуток времени от начала измерения.

\section{3. Экспериментальные результаты и об- суждение \\ 3.1. Чувствительность к метану электро- проводности керамики ZnO-Ag}

Кинетические зависимости изменения отклика образцов исследуемой керамики при их помещении и изъятии из воздушной среды, содержащую метан, представлены на рис. 1.

Как видно, отклик $\Delta \sigma / \sigma_{0}$ образца сенсора растет с увеличением концентрации детектируемого газа в окружающей его воздушной среде (рис. 1 а). Приведенные кинетические зависимости $\Delta \sigma / \sigma_{0}$, измеренные при разных температурах (рис. 1 б), указывают на максимум отклика в диапазоне температур в окрестности $T=523 \mathrm{~K}$.

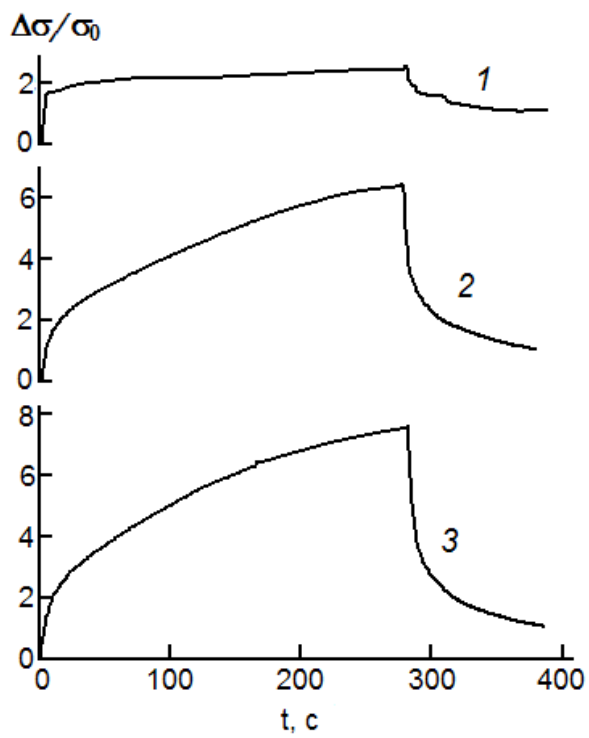

a)

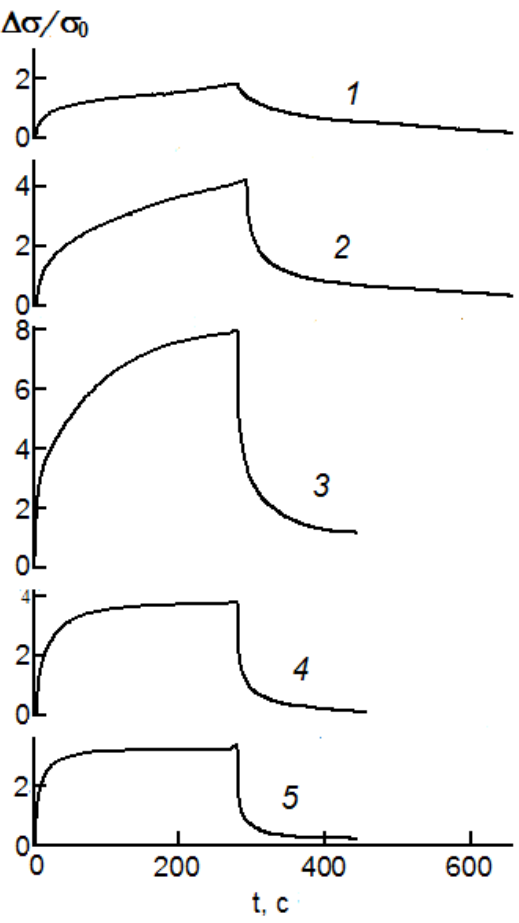

б)

Рис. 1. Кинетические зависимости отклика образца керамического оксида цинка с добавкой оксида серебра ( $v=1,5$ мас.\%) к метану при $T=523$ К и относительных концентрациях метана $n_{C H 4} / n_{0}: 1-10^{-4} ; 2-10^{-3} ; 3-10^{-2}$ (a) и при $n_{C H 4} / n_{0}=\mathbf{0 , 0 0 5}$ температурах $T, \mathrm{~K}: 1-423$; $2-473 ; 3-523 ; 4-573 ; 5$ - 623 (б).

Полученные результаты согласуются с общими закономерностями в кинетике детектирования сенсорами на основе оксида цинка, известными для метана и других восстановительных газов [12, 18, 19].Особенностью исследованных переходных процессов также является тот факт, что при температуре 523 K и ниже кинетические зависимости не достигают насыщения за достаточно длительный промежуток времени действия активного газа (рис. 1 б, кривые 1, 2 и 3). При температурах существенно превышающих $T=523 \mathrm{~K}$ такое насыщение наблюдается (кривые 4 и 5).

Зависимости стационарного значения отклика $\Delta \sigma_{s t} / \sigma_{0}$ (здесь и далее - значения отклика через 300 с после начала измерения, так как $\Delta \sigma / \sigma_{0}$ не всегда выходит на стационарное значение) от концентрации активного газа и температуры представлены на 
рис. 2. С ростом концентрации метана наблюдается его увеличение (рис. 2 а). Температурные зависимости отклика (рис. 2 б) имеют типичный вид для углеводородов [16]: в диапазоне температур 470-620 К зависимость проявляет максимум.

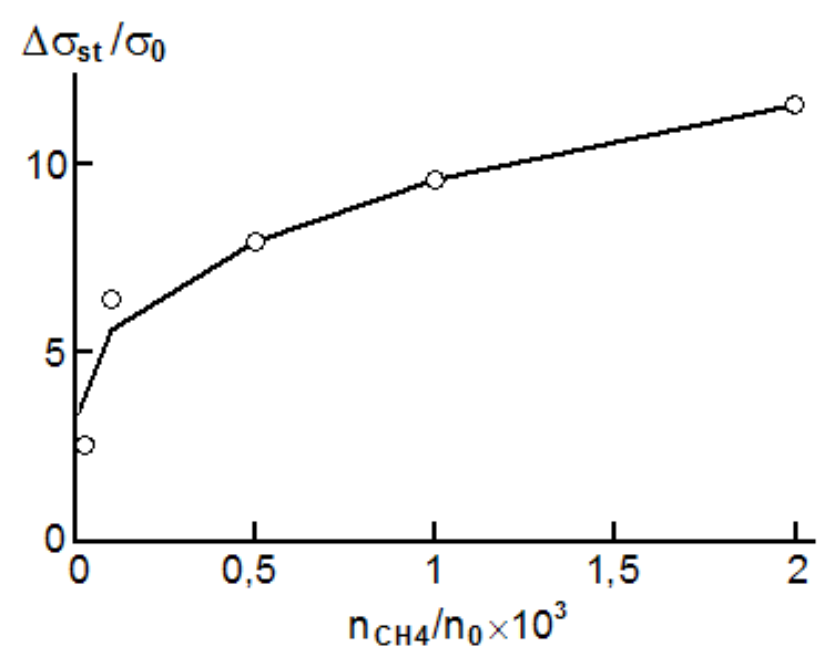

a)

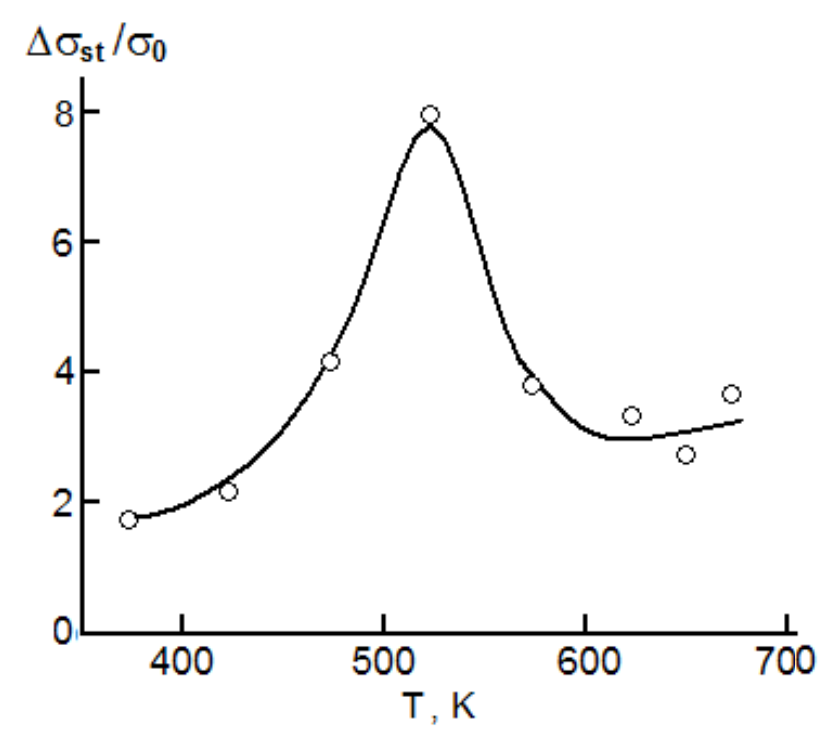

б)

Рис. 2. Зависимости стационарного значения отклика $\Delta \sigma / \sigma_{0}$ образца керамического оксида цинка с добавкой оксида серебра $(v=1,5$ мас.\% при $T=523$ К) от относительной концентрации метана $n_{C H} / n_{0}$ (a) и при $n_{C H} 4 / n_{0}=\mathbf{0 , 0 0 5}$ от температуры (б).

Экспериментальные данные соответствуют известной барьерной модели газочувствитель- ных эффектов [20]. В рассматриваемом случае метан ведет себя по отношению к керамике на основе оксида цинка как донорный газ, то есть, увеличивает ее электропроводность. Наиболее вероятным механизмом такого взаимодействий является взаимодействие углеводородов с предварительно хемосорбированным на поверхности кристаллитов $\mathrm{ZnO}$ кислородом в виде ионов $O_{2}^{-}$и $O^{-}$.

Эти ионы в режиме сенсибилизации сенсора образуют отрицательный поверхностный заряд, который обусловливает обедненные основными носителями заряда поверхностные изгибы энергетических зон кристаллитов. Таким образом, образуются межкристаллитные потенциальные барьеры, определяющие электрическую проводимость рассматриваемой керамики. Их уменьшение в процессе реакции детектирования метана обусловливает увеличение проводимости, что и фиксируется как отклик.

Одним из возможных объяснений того, что зависимость отклика от температуры имеет максимум (рис. 2 б), может являться то, что количество хемосорбированного кислорода на поверхности $\mathrm{ZnO}$ существенно меняется с температурой (в том числе и без присутствия в воздухе метана). С ростом температуры в диапазоне до $\sim 523 \mathrm{~K}$ процесс адсорбции ионов $\mathrm{O}_{2}^{-}$и $O^{-}$интенсифицируется: на поверхности их концентрация увеличивается, что ведет к росту отрицательного поверхностного заряда и высоты потенциального поверхностного барьера. В результате диапазон изменения высоты этого барьера, следовательно, и отклик, при взаимодействии с детектируемым газом возрастает. При дальнейшем повышении температуры равновесие адсорбциядесорбция смещается в сторону десорбции. Исходный межкристаллитный барьер снижается, что ведет к сокращению диапазона возможных изменений электропроводности в процессе детектирования и, следовательно, к снижению отклика.

\section{2. Влияние процентного содержания добавки оксида серебра на газочувстви- тельность керамики}

Кинетические зависимости отклика на воздействие метана для образцов исследуемых 
керамик с разным содержанием добавки серебра представлены на рис. 3.

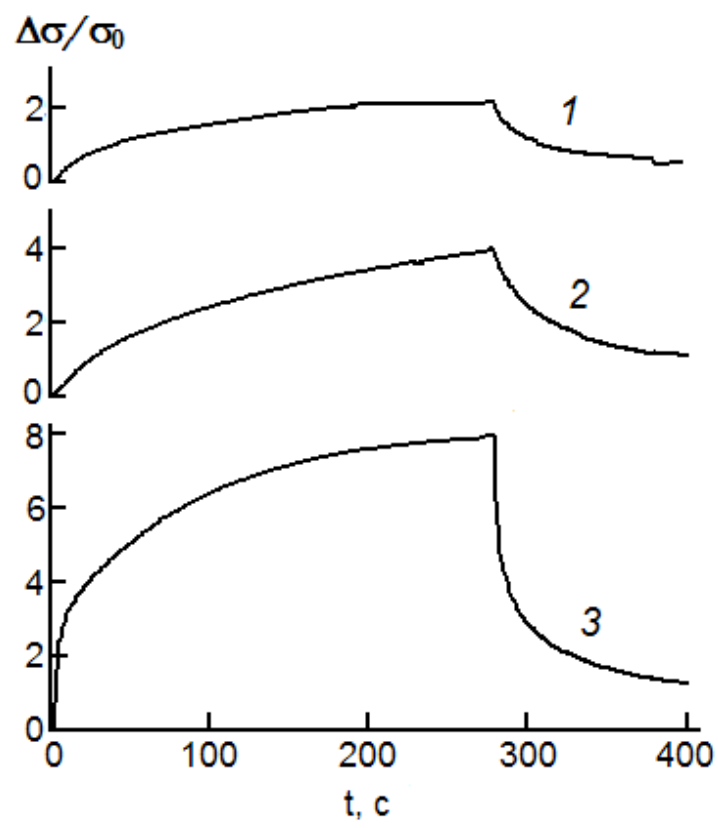

Рис. 3. Кинетические зависимости отклика по отношению к метану $\left(n_{C H} 4 / n_{0}=\mathbf{0 , 0 0 5}\right.$; $T=523$ К) образцов керамического оксида цинка с добавками оксида серебра $v$, мас.\%: 1 - 0;

$$
2-0,01 ; 3-1,5 \text {. }
$$

Как видно при увеличении количества добавки $v$ абсолютная величина $\Delta \sigma / \sigma_{0}$ возрастает. В то же время существенных отличий в кинетике детектирования (увеличения электропроводности) как и в релаксации после воздействия метана не наблюдается.

Такой результат соответствуют представлениям $[12,16]$ о том, что данный эффект обусловлен уменьшением плотности керамического оксида цинка при введении добавки серебра. Об этом свидетельствуют приведенные на рис. 4 зависимости стационарного значения отклика (кривая 1) и плотности (кривая 2) образцов исследуемой керамики $\mathrm{ZnO}$ от содержания добавки оксида серебра, вводимой при ее изготовлении. Кривая 3 демонстрирует линейную зависимость между величиной $\Delta \sigma_{s t} / \sigma_{0}$ и плотностью $r$ образца. Возникающие при этом из-за введения добавки поры увеличивают удельную поверхность образца, которая и является местом протекания молекулярных процессов сенсибилизации и детектирования.
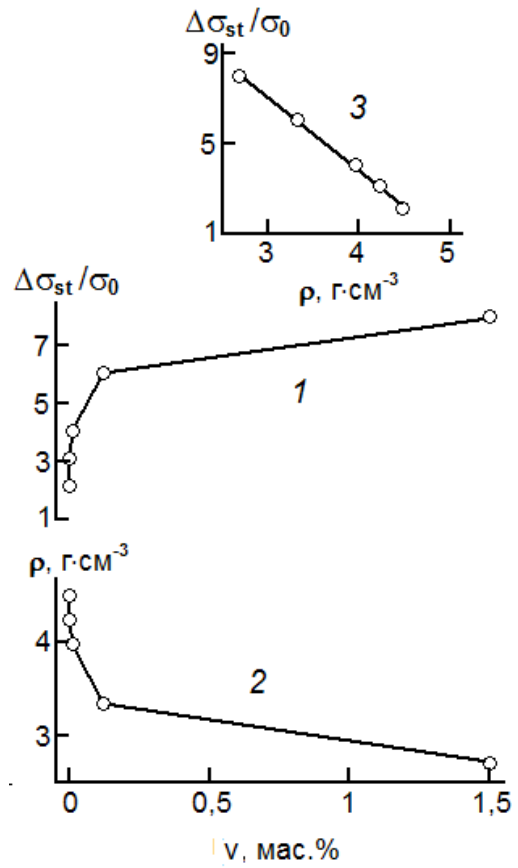

Рис. 4. Зависимости стационарного значения отклика $\Delta \sigma_{s t} / \sigma_{0}$ (1) и плотности образца $\rho$ (2) от содержания добавки оксида серебра $v$ и зависимость $\Delta \sigma_{s t} / \sigma_{0}$ от плотности образца (2). $n_{C H} 4 / n_{0}=\mathbf{0 , 0 0 5} ; T=\mathbf{5 2 3} \mathbf{K}$.

\section{3. Сравнение сенсорных характеристик} керамики ZnO-Ag для метана и пропанбутановой смеси

На рис. 5 приведены зависимости стационарного значения отклика на воздействие метана и технической пропанбутановой смеси. Такое сравнение представляется важным для оценки селективности газочувствительных свойств исследуемого материала. Выбор технической пропан-бутановой смеси обусловлен тем, что данные о сенсорных свойства керамики на ее воздействие уже представлены в литературе [16]. Логарифмический масштаб использован для более наглядного изображения обсуждаемых закономерностей.

Как видно из рис. 5, зависимости отклика образцов исследуемой керамики на воздействие обоих адсорбатов схожи. Концентрационные зависимости $\Delta \sigma_{s t} / \sigma_{0}$ спрямляются в двойных логарифмических координатах (рис. 5 а). Однако, чувствительность керамики на воздействие метана выше при 
малых его концентрациях. При высоких концентрациях использованных адсорбатов наоборот, больший отклик на воздействие пропан-бутановой смеси.

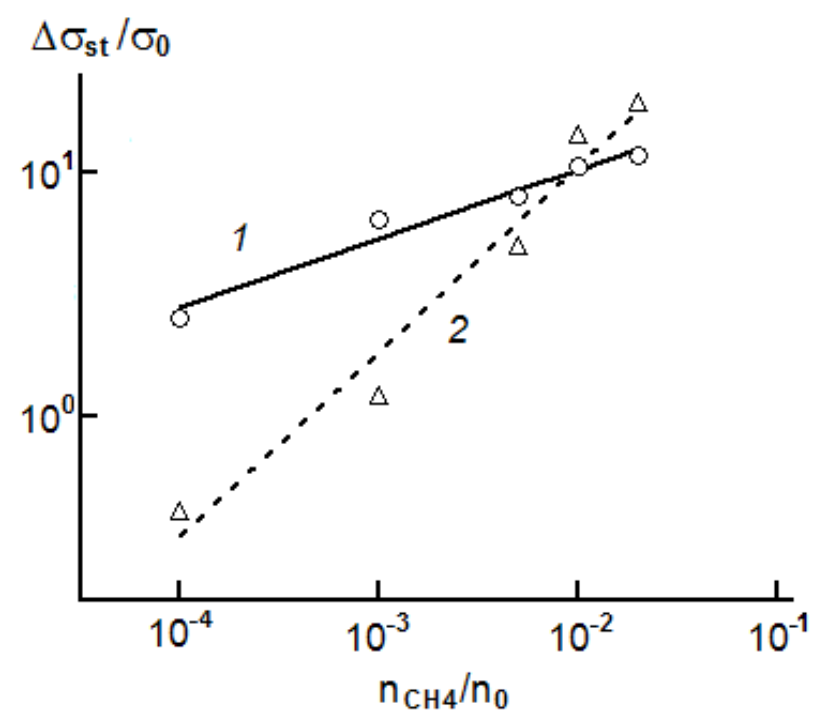

a)

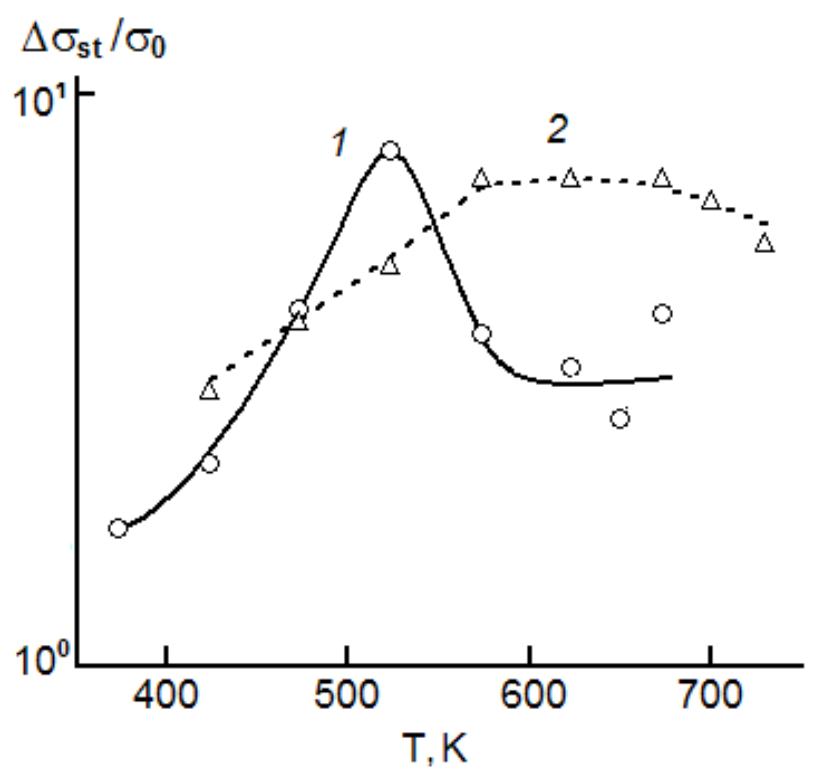

б)

Рис. 5. Зависимости стационарного отклика $\Delta \sigma_{s t} / \sigma_{0}$ образцов керамического оксида цинка с добавкой оксида серебра $v=1,5$ мас.\% при $T=523$ К от относительной концентрации метана (1) и смеси пропана с бутаном (2) (a) и при $n_{C H} 4 / n_{0}=\mathbf{0 , 0 0 5}$ от температуры (б).

Температурные зависимости $\Delta \sigma_{s t} / \sigma_{0}$ имеют максимумы (рис. 5 б). Максимум ука- занных зависимостей для пропан-бутановой смеси более широкий, что, по-видимому, связано с наличием двух углеводородов в ее составе. Максимум наблюдается на более высоких температурах, чем для метана. Этот результат находится в соответствии с данными для паров предельных одноатомных спиртов $[13,14]$ и представлениями о том, что с увеличением молярной массы газообразного углеводорода температура максимума смещается в сторону больших температур.

\section{Выводы}

Керамическая система $\mathrm{ZnO}-\mathrm{Ag}$ обладает достаточно высокой чувствительностью электропроводности к метану, сравнимой с значениями для технической пропанбутановой смеси.

Для описания механизма газочувствительности керамики $\mathrm{ZnO}-\mathrm{Ag}$ по отношению к углеводородам применима барьерная модель. Добавка серебра, вводимая в виде его оксида при изготовлении керамики, приводит к уменьшению плотности образцов и следовательно увеличению удельной поверхности, что в свою очередь приводит к увеличению газочувствительности.

Газовая чувствительность керамики на основе $\mathrm{ZnO}$ имеет некоторую селективность в отношении исследованных нами газообразных углеводородов. Различия наблюдаются в температурных зависимостях отклика, а также в зависимостях отклика от парциального давления. Для углеводородов с более высокой молярной массой максимум температурной зависимости отклика сдвигается в сторону более высоких температур.

\section{Список использованной литературы}

[1]. L.A. Obvintseva. Metal oxide semiconductor sensors for determination of reactive gas impurities in air, Russian Journal of General Chemistry 78 (12) pp. 2545-2555 (2008).

[2]. B. Bhooloka Rao. Zinc oxide ceramic semiconductor gas sensor for ethanol vapor, Mater. Chem. Phys. 64, pp. 62-65 (2000).

[3]. C. C. Hsiao, \& L. S. Luo. A rapid process for fabricating gas sensors. Sensors, 14(7), pp. 12219-12232 (2014). 
[4]. R. Kumar, O. Al-Dossary, G. Kumar, \& A. Umar. Zinc oxide nanostructures for NO2 gassensor applications: a review. Nano-Micro Letters, 7(2), pp. 97-120 (2015).

[5]. Y. Hong, C. H. Kim, J. Shin, K. Y. Kim, J. S. Kim, C. S. Hwang, \& J. H. Lee. Highly selective $\mathrm{ZnO}$ gas sensor based on MOSFET having a horizontal floating-gate. Sensors and Actuators B: Chemical, 232, pp. 653-659 (2016).

[6]. A.Yu. Lyashkov, A.S. Tonkoshkur, I.V. Gomilko. The analysis of gas sensitive effects in the zinc oxide based ceramics systems, Sens. Electron. Microsyst.Technol. 3-7 (in Ukrainian). pp. 45-46 (2006).

[7]. S. S. Karpova, V. A. Moshnikov, S. V. Mjakin, \& E. S. Kolovangina. Surface functional composition and sensor properties of $\mathrm{ZnO}, \mathrm{Fe}_{2} \mathrm{O}_{3}$, and $\mathrm{ZnFe}_{2} \mathrm{O}_{4}$. Semiconductors, 47(3), pp. 392-395. (2013).

[8]. J. Jose, \& M. A. Khadar. Role of grain boundaries on the electrical properties of $\mathrm{ZnO}$ Ag nanocomposites: an impedance spectroscopic study. Acta materialia, 49(4), pp. 729-735 (2001).

[9]. ü. Özgür, Y.I. Alivov, C. Liu, A. Teke, M.A. Reshchikov, S. Dogan, V. Avrutin, S.J. Cho, and H. Morkoç. A Comprehensive Review of $\mathrm{ZnO}$ Materials and Devices. Journal of Applied Physics, 98, Article ID: 041301. http://dx.doi. org/10.1063/1.1992666 (2005).

[10]. S. T. Kuo, W. H. Tuan, J. Shieh, \& S. F. Wang. Effect of Ag on the microstructure and electrical properties of $\mathrm{ZnO}$. Journal of the European Ceramic Society, 27(16), pp. 4521-4527 (2007).

[11]. R. Deng, Y. Zou, \& H. Tang. Correlation between electrical, optical properties and $\mathrm{Ag} 2+$ centers of $\mathrm{ZnO}$ : Ag thin films. Physica B: Condensed Matter, 403(12), pp. 2004-2007 (2008).

[12]. A.Yu. Lyashkov, A.S. Tonkoshkur, J.A. Aguilar-Martinez, A.B. Glot. ZnO-Ag ceramics for ethanol sensors, Ceram.Int. 39 pp. 2323-2330 (2013).

[13]. A. Y. Lyashkov, \& A. S. Tonkoshkur. Gas sensitivity of $\mathrm{ZnO}$-based ceramics to vapors of saturated monohydric alcohols. Materials Chemistry and Physics, 140(1), pp. 31-36 (2013).

[14]. A. Y. Lyashkov, A. S. Tonkoshkur. The selectivity of gas sensitivity of $\mathrm{ZnO}$ ceramics doped with $\mathrm{Ag}_{2} \mathrm{O}$ to alcohol pairs. Sensor Electronics and Microsystem Technologies, 3(9), pp. 70-75 (in Russian) (2012).
[15]. A. I. Uddin, D. T. Phan, \& G. S. Chung. Low temperature acetylene gas sensor based on Ag nanoparticles-loaded $\mathrm{ZnO}$-reduced graphene oxide hybrid. Sensors and Actuators B: Chemical, 207, pp. 362-369 (2015).

[16]. A. Yu. Lyashkov, A. S. Tonkoshkur, E. L. Povzlo. Sensitivity conductivity of the ceramic $\mathrm{ZnO}$ with the addition of silver to propane-butane mixture. Sensor Electronics and Microsystem Technologies, (12, № 2), pp. 71-77 (2015).

[17]. G.P. Khomchenko. Himiya. Vyisshaya shkola, M. 368 s. (1989).

[18]. P. Mitra, \& A. K. Mukhopadhyay. ZnO thin film as methane sensor. Bulletin of the Polish Academy of Sciences-Technical Sciences, 55(3), pp. 281-285 (2007).

[19]. S. Roy, H. Saha, \& C. K. Sarkar. High sensitivity methane sensor by chemically deposited nanocrystalline $\mathrm{ZnO}$ thin film. International journal on smart sensing and intelligent systems, 3(4) (2010).

[20]. I.A. Myasnikov, V.Ya. Sukharev, L.Yu. Kupriyanov, S.A. Zavyalov. Poluprovodnikovyie sensoryi $\mathrm{v}$ fiziko-himicheskih issledovaniyah. Nauka, M. 327 s. (1991).

Стаття надійшла до редакції 30.11.2016 р. 


\title{
SENSITIVITY CONDUCTIVITY OF THE CERAMIC ZnO WITH ADDITION OF SILVER TO METHANE
}

\author{
E. L. Povzlo, A. Yu. Lyashkov, A. S. Tonkoshkur \\ Department of Physics, Electronics and Computer Systems, Dniepropetrovsk National University, \\ Gagarin Av. 72, Dniepro 49010, Ukraine \\ Phone.+380638409592, e-mail:vdnu@yandex.ua
}

\begin{abstract}
Summary
Purpose of the paper was the experimental research of sensitivity of the electrical conductivity of $\mathrm{ZnO}$ ceramics with the addition of silver to the presence of methane in the air environment, and also obtained results were compared with data of gas sensitivity of ceramics to other hydrocarbons.

Research methods. The samples were made of $\mathrm{ZnO}$ powders and $\mathrm{Ag} 2 \mathrm{O}$ submicron ceramic technology. We learned the changes in the electrical conductivity of the experimental samples by placing them in an environment containing methane or other hydrocarbons.

The kinetics of the response was investigated by placing / retrieving the sensor into the measurement cell filled with a mix of air and reactive gas.

We learned the dependence of the response from the time spent in the active medium, from the ceramic temperature and from the concentration of active gas.

Methane was synthesized at the laboratory by heating a mixture of sodium hydroxide and sodium acetate.

We used propane-butane mixture PBA brand (LPG ), containing $50 \pm 10 \%$ of propane, butane, and not more than $6 \%$ of unsaturated hydrocarbons to compare obtained results with the data for other gaseous hydrocarbons

Results of the research. It found that the sensitivity of the leaned ceramics has a certain selectivity. This is detected by the displacement maximum of the temperature dependence of response to higher temperatures for the hydrocarbons with a higher molecular weight (propane, butane) in comparison with methane.

Conclusions. To describe the gas sensitivity $\mathrm{ZnO}-\mathrm{Ag}$ mechanism ceramics in relation to hydrocarbons applicable barrier model.

It is shown that the conductivity of the ceramic has a sufficiently high sensitivity to methane and is comparable with the values for other gaseous hydrocarbons. Its increase can be achieved by adding silver into the ceramic additive that reduces its density.
\end{abstract}

Keywords: Zinc oxide, silver, sensor, gas sensing, electrical conductivity, ceramics, methane, grain boundary 


\title{
ЧУТЛИВІСТЬ ЕЛЕКТРОПРОВІДНОСТІ КЕРАМІКИ ZnO 3 ДОМІШКОЮ СРІБЛА ДО МЕТАНУ
}

\author{
Є. Л. Повзло, О. Ю. Лямков, О. С. Тонкошкур \\ Дніпровський національний університет ім. О. Гончара \\ 49010, Україна, Дніпро, пр. Гагаріна, 72, каф. радіоелектроніки, \\ meл.+380638409592, e-mail:vdnu@yandex.ua
}

\section{Реферат}

Метою роботи було експериментальне дослідження чутливості електропровідності кераміки $\mathrm{ZnO}$ з домішкою срібла до присутності в повітряному середовищі метану, а також зіставлення отриманих результатів з даними про газочутливість цієї кераміки до інших вуглеводнів.

Методика досліджень. Використовувалися зразки, виготовлені з порошків ZnO i $\operatorname{Ag}_{2} \mathrm{O}$ субмікронного розміру по керамічній технології. Вивчалася зміна електропровідності експериментальних зразків при введенні їх до середи що містить метан або інші вуглеводні.

Кінетика відгуку досліджувалася шляхом введення - виведення сенсора в вимірювальну камеру заповнену сумішшю повітря і детектуємого газу.

Досліджувалися залежності відгуку від часу знаходження в активному середовищі, від температури кераміки, від концентрації активного газу.

В експериментах використовувався метан синтезований лабораторним методом шляхом нагрівання суміші гідроксиду натрію та ацетату натрію.

Для порівняння отриманих результатів з даними для інших газоподібних вуглеводнів використовувалася пропан-бутанова суміш марки ПБА (пропан-бутан автомобільний), що містить $50 \pm 10 \%$ пропану, бутан і не більше $6 \%$ ненасичених вуглеводнів.

Результати дослідження. Встановлено, що чутливість дослідженої кераміки має деяку селективність. Це проявляється в зміщенні максимуму температурної залежності відгуку в сторону високих температур для вуглеводнів з більшою молекулярною масою (пропан, бутан) в порівнянні з метаном.

Висновки. Для опису механізму газочутливості кераміки $\mathrm{ZnO}-\mathrm{Ag}$ по відношенню до вуглеводнів може бути застосована бар'єрна модель.

Показано, що досліджена кераміка має досить високу чутливість електропровідності до метану, порівняної зі значеннями для інших газоподібних вуглеводнів. Її збільшення може бути досягнуто введенням в кераміку домішки срібла, що призводить до зменшення ії̈ густини.

Ключові слова: оксид цинку, срібло, сенсор, газочутливість, електропровідність, бутан, пропан, кераміка, міжкристалітні бар'єри 